Ankara Ezc. Fak. Mec.

13. 152 (1983)
J. Fak. Pharm Ankara

13. 152 (1983)

\title{
Türkiye'de Yetişen Bazı Verbascum Türlerinin Flavonoidler Yönünden Karşılaştırılması
}

Flavonoid Contents of Some Verbascum sp. Growing in Turkey

\author{
Erendiz ATAS Ü**
}

GİRIŞ̧ ve AMAÇ

\begin{abstract}
Ülkemizde yaygın olarak yetişen Verbascum (Scrophulariaceae) genusunun bazı türlerinin saponozit, oz, tanen, alkaloıd, uçucu yağ, ve karatoneoid içeriği daha önceki bir çalışmada (1) incelenmişti. Burada aynı türler flavonoid türevleri açısından karşılaştırılacaktır.
\end{abstract}

\section{MATERYAL ve YÖNTEM}

\section{Materyal:}

Çalışılan türler ve toplama yerleri:

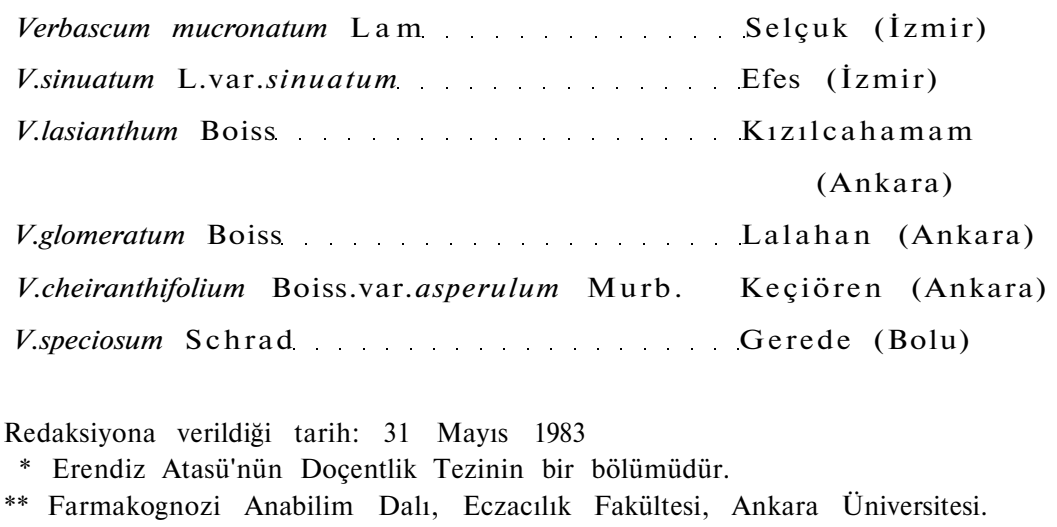


V.insulare Boiss.ve Heldr. . . . . . Şereflikoçhisar

(Ankara)

V.caudatum Freyn ve Bornm.........Beynam (Ankara)

V.vulcanicum Boiss ve Heldr.var.vulcanium Beynam (Ankara)

Ön araştırmalar, gölgede kurutulmuş herba ile; daha sonraki çalışmalar petal ve stamenlerle yapıldı.

\section{Yöntem :}

Flavonoid bileşikleri, taze ve kuru numunelerinin metanollü ekstrelerinde, asit hidrolizden önce ve sonra İ T K ve kağıt kromatografisi yöntemiyle saptand. Ekstrelere karakteristik renk reaksiyonları uygulanarak flavonoid türevlerinin hangi gruba $(2,3)$ girdiği saptand ve ekstrelerin $\mathrm{AlCl}_{2}$ kompleksinin görünür sahada absorbansını ölçmek suretiyle luteolol üzerinden total flavonoid miktar tayini yapıldi (4).

Numunelerden saponozitlerin uzaklaştırılabilmesi ve flavonoid izolasyonu, aşağıdaki şemada gösterildiği biçimde gerçekleştirildi.

Saponozitlerden temizlenmiş flavonoid ekstreleri Silikagel kolonda, değişen oranlarda kloroform-etilasetat karışımlarıyla ayrıl$\mathrm{d}_{1}$.

Flavonoidler fraksiyonlardan:

1) Petrol eteriyle çöktürme,

2) Whatman I kağıtlarında $\mathrm{N}$ Butanol/Asetik asit/su (4/1/5) (4) solvaniyla temizleme,

3) Whatman I kağıtlarında $T$ Butanol/Asetik asit/su (3/1/1) solvanıla (4) temizleme yöntemleriyle izole edildi ve metanol veya eterde kristallendirildi.

Flavonoidler, renk reaksiyonları, UV Spektrumu, standart ile kıyaslama ile tanınd. 
Toz edilmiş korolla ve stamen

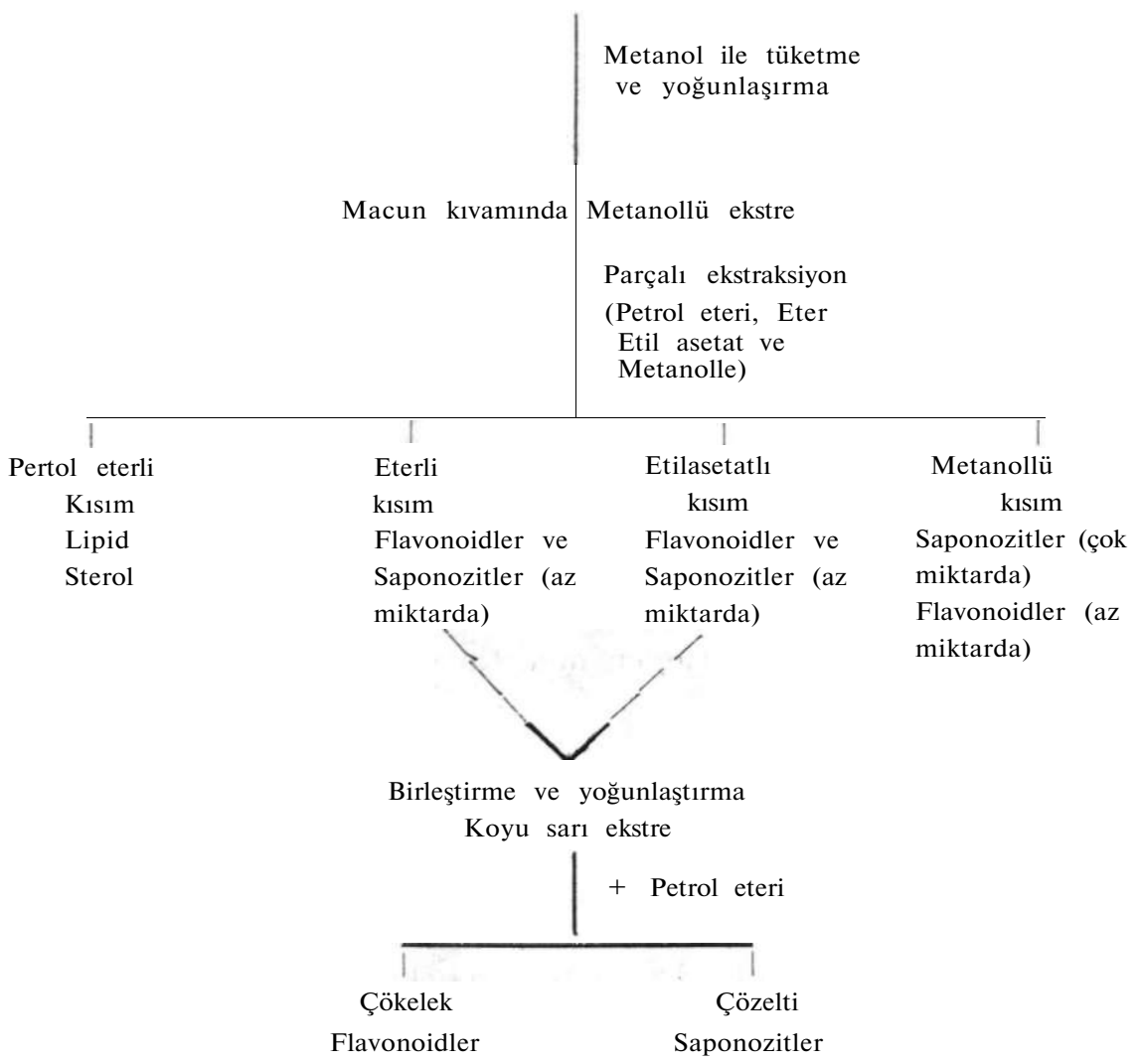

Metanollü kısım

Saponozitler (çok)

ve

Flavonoidler (az)

Yoğunlaştırma

Kovu kahverengi ekstre

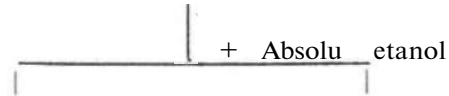

Çözelti Macun kıvamında çökelek

Flavonoidler ve Saponozitler

Saponozitler (az) 
Yoğunlaştırma

Macun kıvamında ekstre

$$
\mid+ \text { Etil asetat }
$$

Etil asetatlı ekstre

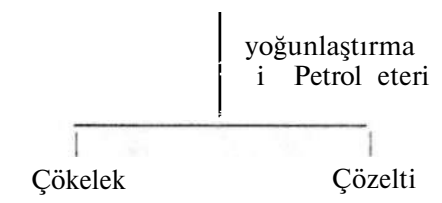

Flavonoidler Saponozitler

\section{BULGULAR}

Taze bitki ekstreleri ve kuru bitki ekstrelori arasında ve asit hidrolizden önce ve sonra ekstreler arasında flavonoid içeriği yönünden İ T K ve kağıt kromatografisiyle bir fark saptanmaması, numunelerdeki flavonoid türevlerinin heterozit biçiminde değil, serbest olarak bulunduğunu gösterdi.

Numunelerin, dal, yaprak ve çiçeklerinde flavonoid içeriği yönünden bir değişim yoktu. Ayrıntılı çalışmalar, Schinoda reaksiyonunu (2) en kuvvetle veren çiçek (petal+stamen) ekstrelerinde yapıldı.

V. lasianthum, $V$. glomeratum, $V$. cheiranthifolium var. asperulum, $V$. speciosum, $V$. insulare, $V$. caudatum, $V$. vulcanicum örneklerinin flavonoid içeriğinin tamamen birbirinin aynı olduğu saptandı. Bu türlerde flavon grubundan dört adet flavonoid bileşiği bulunmaktaydı. Bu bileşikler "Flavon" (a), (b), (c), (d) diye adlandırıldı ve başat bileşiğin Flavon (d) olduğu, Flavon (d) nin de luteolol olduğu saptand. Diğer flavonoidler, üç adet yeni luteolol türeviydi*. Bu türevler, Flavon (a), (b), (c) diye isimlendirildi.

V.mucronatum ve V.sinuatum var. Sinuatum'un falvonoid içeriği diğer türlerden küçük farklar gösteriyordu. Bu türlerde de başat flavonoid bileşiği luteololdu ve sözü edilen yeni luteolol türevleri bu türlerde de vardi. Ancak V.mucronatum'da Flavon (c) bulunuyordu, (a) ve (b) yoktu; V.sinuatum var.sinuatum da ise Flavon (a) bulunuyordu (b) ve (c) yoktu. Kromatogram I)

* Verbascum s.p.'den izole edilen bu yeni luteolol türevleri daha sonraki bir makalede incelenecektir. 
Krom. I. Çeşitli Verbascum Türlerinde Kalitatif Olarak Flavonoid İncelenmesi.

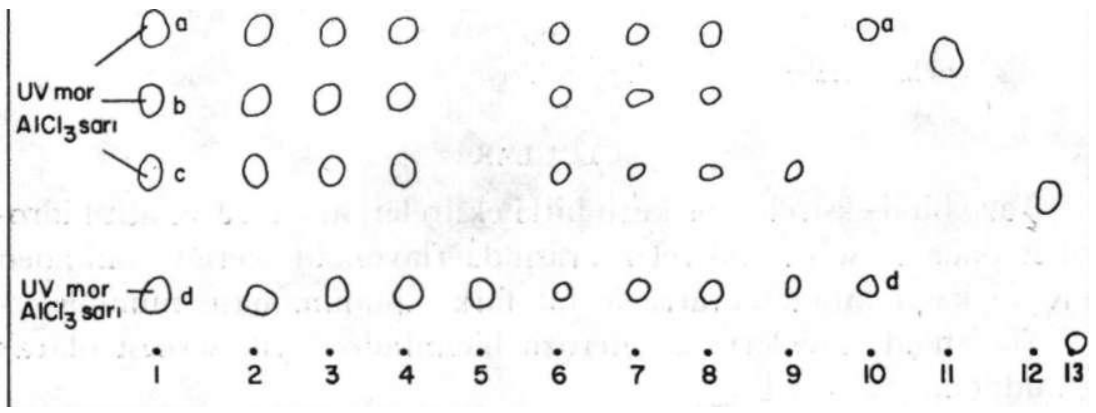

1) V.lasianthum, 2) V.glomeratum, 3) V.cheiranthifolium var. asperulum, 4) V.speciosum, 5) Luteolol, 6) V.vulcanicum, 7) V.caudatum, 8) V.insulare, 9) V.mucronatum, 10) V.sinuatum var.sinuatum, 11) Hesperetol, 12) Apigenol, 13) Rutozit.

İzole edilen flavonoidlerin çeşitli yöntemlerle yapı tayini yapıldı. Başat bileşik Flavon (d) için bulgular aşağıdadır.

E.N. : $320^{\circ} \mathrm{C}$ üstünde bozunma

$\mathrm{C} \quad$ : $\% 62.2 \mathrm{H}: \% 4.005, \mathrm{O}: \% 33.8$

Kromatografide leke görünümü: $U V$ de mor, $U V / \mathrm{NH}_{3}$ da mat sar1: 5-OH, 4'-O H Flavon (4)

Schinoda reaksiyonu (2), portakal renk: Flavon yapısı

Demir (III) klorür (2), yeşil renk: 5-OH flavon yapısı

$\mathrm{ZrOCl}_{2} /$ sitrik asit testi, negatif (3): Flavonol yapısı yok.

İ T K ve kağıt kromatografisinde luteolol ile çakışan leke veriyordu. 
UV Spektrumu verileri $(\lambda, \mathrm{nm})$ :

Metano1, 240, 253, 267, 290, 349: Flavon yapis1

Sodyum metilat, 265, 327, 401: Serbest 4'- OH ve 7 - O H

Alüminyum klorür, 274, 300, 327, 428

Alüminyum klorür/HCl, 265, 274, 293, 356, 384: 5- O H flavon

Sodyum asetat, 269, 324, 385: Serbest $7-\mathrm{OH}$

Sodyum asetat/Borik asit, 256, 300, 370, 428: Serbest 3'-4' dihidroksil

Bulgular Flavon (d) nin lutelolol (5, 7, 3', 4' tetrahidroksi flavon) olduğunu kanıtlamaktadır.

Verbescum numunelerinden elde edilen luteolol türevleri başka bir makalenin konusu olacaktır.

Total Flavonoid miktarı (Luteolol üzerinden hesaplanmıştır):

$\begin{array}{lcc}\text { V.glomeratum } & \% & 1.08 \\ \text { V.cheiranthifolium var.aspelurum } & \% & 0.75 \\ \text { V.lasianthum } & \% & 0.74 \\ \text { V.sinuatum var.sinuatum } & \% & 0.58 \\ \text { V.mucronatum } & \% & 0.40 \\ \text { V.speciosum } & \% & 0.39\end{array}$

DENEYSEL KISIM

\section{Total Flavonoid Miktar Tayini:}

Standart luteolol'un $\mathrm{AlCl}_{3}$ kompleksi (4) $424 \mathrm{~nm}$ de maksimum absorbans göstermekteydi. $0.01 \mathrm{mg} / 10 \mathrm{cc}$ den $0.1 \mathrm{mg} / 10 \mathrm{cc}$. konsantrasyonlardan metanollü standart luteolol çözeltilerinin $424 \mathrm{~nm}$ deki absorbans/konsantrasyon eğrisi çizildi. $50 \mathrm{mg} / 100 \mathrm{cc}$ konsantrasyonlarda hazırlanan metanollü bitki ekstrelerinin $\mathrm{AlCl}_{3}$ kompleksleri de $424 \mathrm{~nm}$ de maksimum absorbans yapmaktaydi. Ekstrelerin $424 \mathrm{~nm}$ deki absorbansları ölçülerek flavonoid konsantrasyonları standart luteolol eğrisinden hesabedildi. 
İ T K : STAHL'a (5) göre hazırlanmış Poliamid ve mikrokristal selüloz plaklarında çalışıldı. Uygun solvan, poliamid için kloroformmetanol-butanon 12/2/1; mikrokiristal selüloz için kloroform-asetikasit-su $(50 / 45 / 5)$ idi. Plaklar $\mathrm{AlCl}_{3}$ belirteci püskürtülmesinden önce ve sonra gün 1 şı̆̆ında ve UV de incelenmiştir.

Kolon kromatografisi: $30 \times 2.5 \mathrm{~cm}$ boyutlarında (0.063-0.200 mm.; 70-230 mesh) Silikagel kolonlarla çalışıldı. Kolon değişen oranlarda kloroform-etilasetat karışımlarıyla elue edildi.

UV Spektrumu: MABRY et al'a göre (4) hazırlanan reaktiflerle ve MABRY et al'ın yöntemine göre Pye-Unicam SP 1700 UV spektrofotometresinde çekildi.

Asit Hidroliz: Önce HARBORNE'a göre (6) sonra güç hidroliz olabilecek heterozit bağlarının varlığını araştırmak amacıyla 6 NHC1 ile 10 saat kaynatmayla yapildi.

Ekstreler: Taze bitki materyali, enzim inaktivasyonunu sağlamak amacıla materyalin kaynar metanole batırılması yoluyla ekstre edildi.

Kuru bitki materyali YÖNTEM bölümünde verilen şemaya göre ekstre edildi.

\section{LİTERATÜR}

1- Atasü, E.: Ankara Ecz.Fak.Mec, 11(1-2), 1982 (Baskıda).

2- Peach, K., Tracey, M.V., Modern Methods of Plant Analysis, Vol. III, Springer-Verlag, Berlin, Göttingen (1955).

3- Hörnhammer, L., Haensel, R., Anh. Pharmaz. 286, 447-452 (1953).

4- Mabry, T.J., Markham, K.R., Thomas, M.B.: The Systematic Identification of Flavonoids, Springer-Verlag, Berlin, Heidelberg, New-York (1970).

5- Stahl, E., Thin Layer Chromatography, George Allen and Union, Springer-Verlag (1969).

6- Harborne, Y.B., Phytochemistry, 4, 107-120 (1965). 